\title{
Review
}

Journal of Innate

Immunity
J Innate Immun 2009;1:70-87

DOI: $\underline{10.1159 / 000181144}$
Received: October 1, 2008

Accepted after revision: October 8, 2008 Published online: December 2, 2008

\section{Corruption of Innate Immunity by Bacterial Proteases}

\author{
Jan Potempa ${ }^{a, b}$ Robert N. Pike \\ ${ }^{a}$ Department of Microbiology, Faculty of Biochemistry, Biophysics and Biotechnology, Jagiellonian University, \\ Krakow, Poland; 'bepartment of Biochemistry and Molecular Biology, University of Georgia, Athens, Ga., USA; \\ 'Department of Biochemistry and Molecular Biology, Monash University, Clayton, Vic., Australia
}

\section{Key Words}

Proteolysis - Virulence $\cdot$ Complement - Antimicrobial

peptides $\cdot$ Protease $\cdot$ Phagocytosis $\cdot$ Inflammation

\begin{abstract}
The innate immune system of the human body has developed numerous mechanisms to control endogenous and exogenous bacteria and thus prevent infections by these microorganisms. These mechanisms range from physical barriers such as the skin or mucosal epithelium to a sophisticated array of molecules and cells that function to suppress or prevent bacterial infection. Many bacteria express a variety of proteases, ranging from nonspecific and powerful enzymes that degrade many proteins involved in innate immunity to proteases that are extremely precise and specific in their mode of action. Here we have assembled a comprehensive picture of how bacterial proteases affect the host's innate immune system to gain advantage and cause infection. This picture is far from being complete since the numbers of mechanisms utilized are as astonishing as they are diverse, ranging from degradation of molecules vital to innate immune mechanisms to subversion of the mechanisms to allow the bacterium to hide from the system or take advantage of it. It is vital that such mechanisms are elucidated to allow strategies to be developed to aid the innate immune system in controlling bacterial infections.
\end{abstract}

Copyright $\odot 2008$ S. Karger AG, Basel

\section{KARGER}

Fax +4161306 1234

E-Mail karger@karger.ch

www.karger.com
(C) 2008 S. Karger AG, Basel

Accessible online at: www.karger.com/jin

\section{Introduction}

An estimated $10^{14}$ commensal microbes inhabit the skin and mucosal membranes of the human body, a number that exceeds the quantity of cells in our bodies by an order of magnitude. In the oral cavity alone, more than 700 different bacterial species are found and commensal bacteria are reported to reach a density of $10^{12} / \mathrm{ml}$ of luminal content in the adult human intestine. These microorganisms engage in a complex network of interactions with the host and an emerging paradigm indicates that they are essential for the development of the immune system and play an active role in host defense against potential pathogens, that is, microbes intrinsically capable of producing symptomatic infectious diseases. In this respect, the normal microflora is part of the mammalian innate immune system that has co-evolved with surrounding microbiota and the host to become a formidable and intelligent defense barrier. The efficiency of this barrier relies on its ability to mount lethal attacks on invading pathogens, while simultaneously tolerating benign co-inhabitants and innocuous microbes found in food, water and inhaled air.

In a broad sense the innate immune system is composed of physical barriers and effector molecules and cells. In the case of cutaneous surfaces (skin), defense occurs through the combined action of several complementary systems. Apart from the sheathing layer of keratin-
Prof. Dr. Jan Potempa

Department of Microbiology, Faculty of Biochemistry

Biophysics and Biotechnology, Jagiellonian University

ul. Gronostajowa 7, PL-30387 Krakow (Poland)

Tel. +48 12664 6343, Fax +48 12664 6902, E-Mail potempa@uga.edu 
ized, water-impermeable epithelium that physically restricts access of microbes to deeper tissues, the barrier is also guarded by a chemical defense system composed of antimicrobial peptides (AMPs; such as cathelicidin, $\beta$ defensins, dermicidin and psoriasin) produced in the accrine sweat glands, mast cells, epithelial cells and keratinocytes as well as the neutrophils and macrophages that infiltrate subepithelial connective tissue. Additionally, fatty acids secreted by the sebaceous glands are key factors in the chemical defense system. Some of these factors are constitutively secreted, while the production of others is greatly induced following any break in epithelial integrity.

Due to the adsorptive and/or secretory functions of the mucosal membranes of airways, reproductive tract and intestine, these host surfaces, which are naturally exposed to microbes, are covered with a thin, nonkeratinized epithelial layer. Nevertheless, various types of mucosal membranes are impermeable to bacteria due to several physical and biochemical adaptations, such as intercellular tight junctions, the discharge and apical attachment of a heavily glycosylated mucin-rich layer and secretion of a broad range of bactericidal peptides and proteins that impede microbial attachment and penetration through even the single layer of epithelial cells. In addition, the antimicrobial defenses of these surfaces are reinforced by the elaborate mucosa-associated lymphoid tissues that are enriched with cells of the innate and adaptive immune systems.

Once the physical barriers described above are breached, the initial recognition of microbial invaders is mediated by a set of germline-encoded pattern-recognition receptors (PRRs) that sense highly conserved microbial motifs (for example, peptidoglycan, lipopolysaccharide, lipoteichoic acid, lipoproteins, CpG DNA, flagellin, $\beta$-glucan and mannan) referred to as pathogen-associated molecular patterns. PRRs are found in soluble forms in the extracellular space (such as lipopolysaccharidebinding protein, C-reactive protein, mannose-binding lectin as well as surfactant proteins A and D) signaling through membrane-anchored co-receptors or working as opsonizing agents, integrated into cellular membranes (such as Toll-like receptors and CD14) and in the cytosol of cells (such as NOD-like receptors). Engagement of PRRs activates intracellular signaling, leading to the expression of pro-inflammatory cytokines, chemokines and antibacterial soluble effector molecules. Furthermore, activation of the complement system, an essential part of innate immunity, sounds a powerful alarm signal in the form of released anaphylatoxins (C3a and $\mathrm{C} 5 \mathrm{a}$ ).
Chemokines and anaphylatoxins attract neutrophils from the circulation and prime them to unleash formidable bactericidal activity. Together, these processes initiate acute inflammation, which is indispensable for efficient elimination of invading microbes. Monocytes are also mobilized by $\mathrm{C} 3 \mathrm{a}$ and chemokines to migrate into the inflamed tissue, whereupon they undergo a transformation into macrophages. Monocyte/macrophage and neutrophils are professional phagocytes and, together with natural killer cells, constitute the effector cells of innate immunity. While the destiny of neutrophils is to kill microbes and then succumb to apoptotic cell death, macrophages are long-lived. Although macrophages efficiently phagocytose and kill bacteria, these cells are also crucial for the resolution of inflammation and the initiation of tissue repair processes, in addition to their regulation of the adaptive immune response to the microbial infection.

In addition to the classical components of innate immunity described above, a growing body of evidence indicates that other systems are also essential for our innate resistance to microbial infections. The best example is the coagulation cascade. Converse to the conventional paradigm describing coagulation as an entirely separate system that has arisen to prevent bleeding from injured blood vessels, it is now clear that coagulation and innate immunity have co-evolved early in eukaryotic development. These systems now continue to function as a highly integrated unit for defense, following mechanical or infection-induced tissue injury [1]. The localized deposition of a fibrin/platelet mesh following contact activation in response to bacteria walls off the infection and exposes the entrapped intruder to bactericidal peptides, which are released from platelets, and kininogen. Indeed, the contact system is now recognized as a branch of innate immunity [2].

Protease-activated receptors (PARs) constitute another direct link between coagulation and innate immunity. These receptors, which are ubiquitously expressed on epithelial and endothelial cells as well as leukocytes, when activated by proteases of the coagulation cascade are important mediators of innate immunity responses. PARs regulate various functions of leukocytes and activate proinflammatory signaling networks. In the light of strategic tissue distribution and the broad spectrum of proteases that activate PARs, they can be considered as being an integral part of the host antimicrobial alarm system [3-6]. A similar function is ascribed to epithelial integrin receptors [7]. 
Despite these formidable innate immune defenses, humans suffer from infectious diseases caused by bacteria. Bearing in mind that bacterial pathogens have co-evolved with metazoan antimicrobial defenses, it is perhaps not surprising that pathogens have evolved the means to breach the host defenses constituted by both the innate and adaptive immune systems. Human skin is impervious to microbial attack and no bacterial pathogen is able, unaided, to penetrate through the intact keratinized epithelial layer and thus all topical infections start through skin abrasions or via bites of blood-sucking insects. Unfortunately, the innate immunity system of mucosal membranes is more easily compromised and most bacterially mediated infectious diseases begin after breach of this barrier. Nevertheless, only bacteria that are equipped with the appropriate means to bypass, inactivate or hijack host defenses are capable of this activity. The spectrum of virulence traits allowing pathogens to survive the antibacterial activities of innate immunity is astonishing. Some of these tactics rely on proteolytic activity elaborated by the pathogens. This comes as no surprise if one takes into account that the effector and signaling molecules of innate immunity are proteins and peptides that can be inactivated by bacterial proteases. A brief description of bacterial proteases affecting innate immunity is presented in table 1 .

\section{Subversion of Contact Activation Pathway by Bacterial Proteases}

Growing evidence indicates that the contact system, also known as the intrinsic pathway of coagulation or the kallikrein/kinin system, is the integral part of innate immunity. When activated on the bacterial cell surface, the system delivers bactericidal peptides derived from kininogen and entraps bacteria in the thrombus, while the major effector peptide, bradykinin (BK), stimulates macrophages and induces an influx of neutrophils. BK and its metabolite, desArg9BK, are potent inflammatory mediators causing hypotension, increased vascular permeability, edema formation, fever and pain (for review, see Frick et al. [2]) [8, 9].

Several bacterial species produce proteases which either directly release kinins from degraded kininogens or can activate proteases of the contact system (factor XII and plasma prokallikrein) which subsequently release kinins. This first mode of kinin release is exemplified by the action of staphopains from Staphylococcus aureus [10], streptopain (SpeB) of Streptococcus pyogenes, a pro- tease of Streptomyces caespitosus and the Lys- (Kgp) and Arg-specific (Rgp) gingipains of Porphyromonas gingivalis working in concert [11]. Activation of contact factors is a more widespread mechanism and several proteases from pathogenic bacteria have been described to activate either factor XII or prekallikrein or both (for references, see Frick et al. [2]). It is assumed that the vascular permeability induced by the released kinins promotes an influx of plasma containing nutrients into the site of infection and facilitates spreading of the microorganisms. Indeed, it was shown that transvascular dissemination of $P$. gingivalis is dependent upon activation of the contact system [12]. Also, invasion of the systemic circulation by Pseudomonas aeruginosa was aided by BK generated by pseudomonal proteases [13]. Conversely, in an animal model of $S$. pyogenes infection, inhibition of the contact system promoted bacterial dissemination and growth [14]. This indicates that different pathogens have different abilities to counter the antibacterial activity of the contact system, from being susceptible through to subversion for their own benefit.

\section{Escaping Host Defenses by Manipulating Fibrinolysis}

The host inflammatory response to bacterial infection results in local thrombosis and microvascular occlusion important for the isolation of the infectious focus and prevention of the systemic spread of invading microorganisms. To counteract the entrapment, bacterial pathogens have frequently evolved the strategy of hijacking plasmin(ogen), a powerful fibrinolytic protease present at a high concentration in serum. Normally, activation of plasminogen is tightly controlled by activators and inhibitors, but some strains of pathogenic or even commensal bacterial species are able to bypass the checkpoints and use this component of the host fibrinolytic pathway for their own benefit, including dissemination within the host and evasion of host inflammatory immune responses. This 'illegitimate' use of the fibrinolytic system is achieved either by (1) immobilization of plasmin(ogen) on the bacterial surface where it becomes activated by host plasminogen activators, or (2) by production of bacterial surface-associated activators that specifically interact with plasminogen and activate it by complex formation or by proteolysis [15].

Recruitment of plasminogen is a strategy utilized by large numbers of different bacterial species, both pathogenic and commensal. Interestingly, the most commonly 
Table 1. Bacterial proteases and their targets in the innate immune system

\begin{tabular}{|c|c|c|c|}
\hline Protease name(s) & $\begin{array}{l}\text { Catalytic type/clan/ } \\
\text { family (a) }\end{array}$ & Targets & Pathogen \\
\hline Staphopain A (ScpA) & cysteine/CA/C47 & contact activation (HMWK) & Staphylococcus aureus \\
\hline Staphopain B (SspB) & cysteine/CA/C47 & $\begin{array}{ll}1 & \text { contact activation (HMWK) } \\
2 & \text { phagocytes (neutrophils and monocytes) }\end{array}$ & S. aureus \\
\hline Aureolysin & metallo/MA/M4 & $\begin{array}{ll}1 & \text { AMPs (LL-37) } \\
2 & \text { cytokine receptors (IL-6R) }\end{array}$ & S. aureus \\
\hline Pla (plasminogen activator) & aspartyl/AF/A26 & fibrinolysis (plasminogen, $\alpha_{2}$-antiplasmin) & Yersinia pestis \\
\hline PgtE (OmpE, protein E) & aspartyl/AF/A26 & $\begin{array}{l}1 \text { complement (C3b, C4b, C5) } \\
2 \text { AMPs (LL-37) }\end{array}$ & $\begin{array}{l}\text { Salmonella enterica serovar } \\
\text { Typhimurium }\end{array}$ \\
\hline Gelatinase (GelE, coccolysin) & metallo/MA/M4 & $\begin{array}{ll}1 & \text { complement (C3) } \\
2 & \text { AMPs (LL-37) } \\
\end{array}$ & Enterococcus faecalis \\
\hline YopJ/YopP & cysteine/CE/C55 & inflammatory signaling pathway & $\begin{array}{l}\text { Yersinia pseudotuberculosis, } \\
\text { Yersinia enterocolitica }\end{array}$ \\
\hline SseL (ElaD) & cysteine/CE/C79 & inflammatory signaling pathway (deubiquitination) & $\begin{array}{l}\text { S. enterica serovar } \\
\text { Typhimurium }\end{array}$ \\
\hline ChlyDub1 and ChlyDub2 & cysteine/CE/C48 & $\begin{array}{l}\text { inflammatory signaling pathway (deubiquitination and de- } \\
\text { NEDDylation) }\end{array}$ & Chlamydia trachomatis \\
\hline XopD & cysteine/CE/C48 & inflammatory signaling pathway (de-SUMOlylation) & Xanthomonas campestris \\
\hline YopT & cysteine/CA/C58 & actin polymerization (small GTPases) & Y.pestis \\
\hline AvrPphB & cysteine/CA/C58 & intracellular signaling (small GTPases) & Pseudomonas syringae \\
\hline Anthrax lethal toxin & metallo/MA/M34 & inflammatory signaling pathway (MKK) & Bacillus anthracis \\
\hline SufA & serine/SB/S8 & AMPs (LL-37) & Finegoldia magna \\
\hline ZapA (mirabilysin) & metallo/MA/M10 & $\begin{array}{l}1 \text { AMPs (LL-37, hBD1) } \\
2 \text { complement (C1q and C3) }\end{array}$ & Proteus mirabilis \\
\hline
\end{tabular}


Table 1 (continued)

\begin{tabular}{|c|c|c|c|}
\hline Protease name(s) & $\begin{array}{l}\text { Catalytic type/clan/ } \\
\text { family }\end{array}$ & Targets & Pathogen \\
\hline Elastase (LasB, pseudolysin) & metallo/MA/M4 & $\begin{array}{ll}1 & \text { AMPs (LL-37) } \\
2 & \text { PAR-2 } \\
3 & \text { chemokines (RANTES, MCP-1, ENA-78) } \\
4 & \text { cytokines (IL-6, IL-8, IFN- } \gamma \text { ) } \\
5 & \text { cytokine receptors (IL-6R) } \\
6 & \text { phagocyte functions (uPAR, fMLP receptor) }\end{array}$ & Pseudomonas aeruginosa \\
\hline LasA protease (staphylolysin) & metallo/MO/M23 & AMPs (IFN- $\gamma$, IL-2) & P. aeruginosa \\
\hline LepA & serine/SB/S8 & PARs & P. aeruginosa \\
\hline Serralysin & metallo/MA/M10 & $\begin{array}{ll}1 & \text { PAR-2 } \\
2 & \text { cytokine receptors (IL-6R) }\end{array}$ & Serratia marcescens \\
\hline Msp peptidase & metallo/MA/M4 & cytokines (IL-2) & Legionella pneumophila \\
\hline
\end{tabular}

GAS $=$ Group A streptococcus

${ }^{1}$ Classification of proteases is based on the evolutionary and structural relationship among enzymes, inferred from the comparison of amino acid sequence and/or tertiary structures. The term family is used to describe a group of proteases in which members show reciprocal evolutionary relationship. Families are clustered into clans. A clan contains all the present proteases that evolved from a single origin. For details see the MEROPS database: http://merops.sanger.ac.uk.

used plasmin(ogen) receptors on the bacterial surface are cytoplasmic proteins, especially those from the glycolytic metabolic pathway, including glyceraldehyde-3 phosphatase dehydrogenase and enolase. Besides these cytoplasmic proteins, several bacteria express unique cell surface-associated proteins with affinity for plasmin(ogen). Regardless of their structure, all of these receptors work as cofactors for plasminogen activation via the host-derived plasminogen activators, uPA and tPA. In the case of numerous streptococcal species (excluding S. pneumoni$a e$ ), immobilized plasminogen can also be activated by a bacterially derived activator, streptokinase. Significantly, plasmin bound to bacterial surface receptors is insensitive to inhibition by $\alpha_{2}$-antiplasmin, thus promoting pericellular fibrinolysis and degradation of components of extracellular matrix. This induces inflammation and may facilitate dissemination of the bacteria, even those that do not express their own proteolytic activity capable of disrupting the extracellular matrix. Indeed, for several pathogens a correlation was found between their ability to immobilize plasmin(ogen) and the pathogenic outcome of infection $[16,17]$. This relationship was best investigated in the case of Borrelia burgdorferi, the vectorborne spirochete responsible for Lyme disease, where subversion of the fibrinolysis system is important in both the tick and within the infected host [18]. Conversely, the role of exploitation of plasmin(ogen) by commensal and probiotic bacteria in their interactions with the host is unknown.

The second strategy for subverting fibrinolysis depends on the expression of specific plasminogen activators by various bacterial species. Streptokinase and staphylokinase produced by $S$. pyogenes and S. aureus, respectively, are prototypes for this group of proteins. Although structurally unrelated, both proteins form a tight complex with plasminogen inducing conformational changes, so that the plasminogen molecule is converted into plasmin $[19,20]$. Streptokinase is produced by group A, $\mathrm{C}$ and $\mathrm{G}$ streptococci, including species pathogenic for animals, and shows strong preference for binding and activating plasminogen derived from an appropriate host, while having little activity against plasminogen for other animals. In this way, streptokinase from $S$. pyogenes is specific for human plasminogen, which has complicated assessment of this protein's function in the pathogenesis of group A streptococcal infections using animal models. Recently, however, the essential role of streptokinase in $S$. pyogenes infectivity was documented using a humanized 
plasminogen mice model [17]. It was also shown that plasmin immobilization by PAM on the surface of $S$. pyogenes was essential for full exploitation of the host fibrinolytic system to facilitate establishment of infection and subsequent invasion. Finally, the important function of fibrin deposition in limiting bacterial spread from the infectious nidus was documented. Together, these data strongly argue that activation of plasminogen by streptokinase leads to accelerated clearance of host fibrin and is a central mechanism for group A streptococcal invasion and spread.

In contrast to the streptokinase-plasminogen complex, the plasmin activity of the staphylokinase-plasminogen complex is efficiently inhibited by the serpin, $\alpha_{2}$-antiplasmin. In addition, staphylokinase requires fibrin as a cofactor for plasminogen binding. The binding of the tertiary complex to the $S$. aureus surface enhances staphylokinase-induced plasminogen activation and the immobilized plasmin activity is impervious to host protease inhibitors. This is considered important in the escape of $S$. aureus from thrombotic occlusions, but no direct experimental evidence for this has yet been published. Conversely, staphylokinase has several other virulence-related properties, including the ability to inactivate bactericidal peptides (see below).

In contrast to streptokinase and staphylokinase, which are not proteolytic enzymes per se, a few bacterial species have evolved effective plasminogen activators that work in a manner similar to that exerted by host activators, tPA and uPA. Bacterial plasminogen activators belong to the omptin family (family A23) of aspartyl proteases found among the Gram-negative Enterobacteriaceae, including Yersinia sp., Shigella sp. (SopA), Salmonella sp. (OmpE and PgtE), Vibrio fisheri, Legionella pneumophila, Escherichia coli (OmpT), Enterobacter sp., Mesorhizobium sp., Erwinia sp. and Agrobacter tumefaciens [21]. Omptins are integral outer membrane proteins with a characteristic 10 -stranded antiparallel $\beta$-barrel structure that protrudes far above the lipid bilayer into the extracellular space with the catalytic site located in a groove at the top of the vase-shaped extracellular $\beta$-barrel. Although several omptins can activate plasminogen, only the Pla peptidase from Yersinia pestis is a potent plasminogen activator. Interestingly, however, OmpT can be easily converted into an efficient plasminogen activator by subtle mutations at surface-exposed loops: this conversion may represent an interesting example of the evolution of a potent virulence factor from a housekeeping protein. In the case of PgtE from Salmonella enterica and Pla of Yersinia pseudotuberculosis, the $\mathrm{O}$-antigen of lipopolysaccaride steri-

Corruption of Innate Immunity by Bacterial Proteases cally prevents recognition of high-molecular-weight substrates, rendering the plasminogen activator activity cryptic in these enteropathogens. The $\mathrm{O}$-antigen repeats also prevent plasminogen activation by the Pla peptidase and, in this context, it is suggested that the loss of the genetic locus involved in $\mathrm{O}$-antigen synthesis by $Y$. pestis is an adaptation for high virulence [22].

Although some omptins are implicated as important virulence factors (see Inactivation of Bactericidal Peptides), they are generally considered housekeeping enzymes that are unable to generate plasmin from plasminogen. The startling exception is the plasmid-encoded plasminogen activator (Pla) of $Y$. pestis. Pla activates plasminogen by limited proteolysis and also proteolytically inactivates $\alpha_{2}$-antiplasmin which controls plasmin. The enzyme is indispensable for dissemination of $Y$. pestis into the lymph nodes and blood circulation in subdermal, subcutaneous and intradermal infection models, but expendable for virulence after intravenous inoculation [23, 24]. The importance of plasminogen for pathogenicity of $Y$. pestis is apparent from the fact that plasminogen-deficient mice are resistant to infection. In the absence of plasminogen or during infection with Pla-deficient bacteria, robust accumulation of inflammatory cells at sites of infection was observed, strongly correlating with increased survival of the animals. In stark contrast, infections of control mice with wild-type $Y$. pestis led to the formation of widespread foci with massive numbers of extracellular bacteria and little infiltration of inflammatory cells [25]. The survival benefits gained by the elimination of either bacterial Pla or host plasminogen were abrogated by fibrinogen deficiency. Cumulatively, these data indicate that plasminogen and fibrinogen are strongly engaged in the modification of the inflammatory response in vivo and constitute critical determinants of bacterial virulence and host defense [26]. Accordingly, plasminogen is employed by bacteria to not only to escape their entrapment, but also to suppress local inflammation and increase virulence.

\section{Bacterial Proteases Targeting and Manipulating Intracellular Inflammatory Signaling Pathways of Innate Immunity}

Detection of pathogens by PRRs causes a rapid activation of the mitogen-activated protein kinase (including extracellular signal-regulated kinase, natural killer and p38 pathways) and nuclear factor- $\kappa \mathrm{B}(\mathrm{NF}-\kappa \mathrm{B})$ signaling pathways. This leads to the production of pro-inflamma- 
tory cytokines and the initiation of a complete innate immunity response, including the mobilization of neutrophils, activation of macrophages and release of bactericidal compounds. The signaling cascade is regulated by reversible, covalent modification of engaged factors by phosphorylation (kinases and phosphatases) and the attachment of ubiquitin or small ubiquitin-like modifier (SUMO) moieties. SUMO, which is structurally similar to ubiquitin, is a member of a large family of reversible posttranslational modifiers. Like ubiquitin, SUMO utilizes conjugation machinery to form a covalent isopeptide bond between the $\varepsilon$-amino group of a lysine residue in the target protein and the $\mathrm{C}$-terminal glycine residue of SUMO. However, unlike ubiquitination, sumoylation of proteins does not target them for degradation by the proteosome. Both SUMO and ubiquitin moieties can be removed from conjugated proteins by the action of specific isopeptidases. This process of reversible covalent modification plays an essential regulatory role in all eukaryotic organisms. Since prokaryotes lack the ubiquitin or SUMO signaling machineriy, targeting of these systems by virulence factors seems to be an attractive strategy for the microorganism. Indeed, some bacteria have acquired the ability to disrupt these signaling pathways by injecting specific proteins with isopeptidase activity into the host cells. These effectors not only shut down signal transduction, but also eliminate macrophages by forcing affected cells to undergo apoptois [27]. In this respect, the Yersinia species, including Y. pestis, the causative agent of plague, and $Y$. pseudotuberculosis and $Y$. enterocolitica, which generate gastroenteritis and lymphadenitis, respectively and occasionally systemic infection, are master manipulators.

All pathogenic Yersinia species bear a large virulence plasmid, which encodes a type III secretion system (T3SS), together with an array of effector molecules. Effector molecules of the T3SS, including YopJ, are injected directly into host cytosol through a needle-like structure. YopJ is homologous to clan CE of cysteine proteases, a family of proteases encompassing deubiquitinating and de-SUMOylating enzymes. Originally it was proposed that YopJ shuts down pro-inflammatory signaling pathways by hydrolysis of the isopeptide bond in SUMO conjugates [28]. Later, however, it was demonstrated that YopJ is a promiscuous deubiquitinating (DUB) enzyme that cleaves both Lys48 and Lys63-linked polyubiquitin [29]. Several studies have implicated YopJ and its homologue from Y. enterocolitica (YopP) in the disruption of ubiquitination of several signal transmitters of interferon, NF-kB and mitogen-activated protein kinase signal- ing pathways [30-32]. Recently, it was found that YopJ is not a protease, but rather has acetyltransferase activity. It was proposed that YopJ/P acetylates host MMPK kinases (MKK6 and MEK2), thus blocking their subsequent phosphorylation and activation [33]. It still remains possible that YopJ/P has both protease and acetyltransferase activities, but regardless of the precise mechanism, the major consequence of Yersinia infection is YopJ/P-mediated death of macrophages and the inactivation of innate immunity pathways dependent on these cells.

The family of YopJ-like proteins (family C55 of cysteine proteases) is limited to bacteria, where they are found in a variety of animal and plant pathogens as well as in the plant symbiont, Rhizobium. All of these bacteria use T3SS to inject effectors into the host cell cytoplasm. To date, only a handful of YopJ-like effectors have been characterized. Regardless of whether the YopJ-like molecules are unusual hydrolases that have evolved into acyltransferases [34] or are true proteases, all of them are effective manipulators of host innate immunity, both in animals and plants (online supplementary table S1, see www.karger.com/doi/10.1159/000181144). In addition to YopJ-like factors, several pathogenic bacteria encode proteins distinctly related to Ubl-specific proteases of family C48. SseL of S. enterica, serovar Typhimurium, contributes to systemic virulence during murine typhoid-like disease by promoting delayed macrophage cytotoxicity [35]. SseL was unambiguously demonstrated to have deubiquitinating activity both in vivo and in vitro [35]. This activity of SseL is responsible for the suppression of $І \kappa B$ ubiquitination and degradation, thus preventing subsequent NF- $\kappa \mathrm{B}$ activation [36]. Chlamydia trachomatis expresses 2 proteinases (ChlyDub1 and ChlyDub2) which were shown to cleave both ubiquitin and NEDD8 (a ubiquitin-like protein) conjugates [37]. In addition, a very efficient and specific deubiquitinating enzyme, ElaD, is produced by E. coli [38]. Importantly, ChlyDubs and ElaD are only expressed by pathogenic strains of the bacteria and in the case of E. coli, ElaD production is further limited to intestinal pathogenic strains [38]. This strongly suggests that, similarly to SseL of Salmonella sp., these proteases contribute to pathogenicity by interfering with the NF- $\kappa \mathrm{B}$ pathway of the innate immunity response to infection.

Interestingly, a small group of plant and animal pathogens (online suppl. table S2) apparently possess true SUMO isopeptidases grouped into the C48 family of the $\mathrm{CE}$ clan of cysteine proteases. The predicted catalytic domains of these proteins are so similar to eukaryotic ubiquitin-like protein proteases that it is speculated that the 
bacteria acquired these effectors by capturing an eukaryotic UPL1-like gene. To date, only the XopD cysteine protease of Xantomonas campestris has been characterized at the functional, biochemical and structural levels [39]. XopD is injected into plant cells by the T3TT during $X$. campestris pathogenesis, then translocated to subnuclear foci where it hydrolyzes SUMO-conjugated proteins in vivo and thereby contributes to pathogenesis by disrupting host defensive signals in the infected plant cells.

Another group of proteolytic virulence factors affecting the host immune response from within cells are the cysteine proteases related to YopT of $Y$. pestis and AvrPphB of Pseudomonas syringae (online suppl. table S3). YopT cleaves posttranslationally modified RhoA, Rac and Cdc42 GTPases near their carboxy termini, Nterminal to the prenylated cysteine by which these proteins are attached to the membrane [40]. Once released from the membrane, they are no longer able to function in cell-signaling pathways. This leads to disruption of the cytoskeleton in host cells, since small GTPases are essential for the control of actin polymerization. Macrophages affected in this way are disarmed of their ability to phagocytose bacteria, which is indispensable for innate immunity. Similarly, prenylated small GTPases and the host serine/threonine kinase, $\mathrm{PBS} 1$, are substrates of AvrPphB in plant cells. This leads to the onset of the disease in sensitive plants manifested as a hypersensitive response.

In contrast to the factors discussed above, which are injected directly into the host cell, the anthrax toxin of Bacillus anthracis is internalized by endocytosis. After the toxin translocates from endosomes into the cytoplasm, its metalloprotease component, referred to as lethal toxin, cleaves MKKs and thus effectively blocks activation of NF- $\mathrm{BB}$ target genes [41]. As a very specific protease, the lethal factor is a very good target for therapeutic inhibitor development.

\section{Effect on Complement}

The complement system is an integral and vital part of the innate and adaptive immune systems. The system can be activated via 3 pathways: the classical pathway, activated usually by antigen-antibody complexes, the lectin pathway, activated by carbohydrate arrays found on microbial surfaces, and the alternative pathway, activated by $\mathrm{C} 3$ binding to the surface of microorganisms. The classical and lectin pathway recognition molecules are associated with proteases that activate downstream proteins to form the C3 and C5 convertase complexes, while C3 binding to microorganisms attracts unique proteases of the alternative pathway that form differently composed C 3 and C5 convertase complexes. Thus, the C 3 and C5 convertase complexes are pivotal for all mechanisms of activation of the complement system. Downstream activation of further components of the system from $\mathrm{C} 5$ results in formation of the membrane attack complex, which forms pores in the membranes of microorganisms, causing their lysis. This is the most direct effect of complement, but equally as important is the activation of the inflammatory system by the $\mathrm{C} 3 \mathrm{a}$ and $\mathrm{C} 5 \mathrm{a}$ fragments that are cleaved from their parent molecules during complement activation. These molecules are responsible for potent attraction of white blood cells to sites of infection and therefore form a link between the innate and adaptive immune systems. Additionally, coating of the microorganisms by complement molecules opsonizes the organisms, rendering them capable of being recognized by complement receptors on white blood cells, particularly macrophages, which phagocytose and degrade the pathogens. The complement system is regulated by molecules such as the serpin, C1-inhibitor, which inhibits the initiating proteases of the classical and lectin pathways, by molecules such as $\mathrm{C} 4$-binding protein which regulate the formation of the convertase complexes and decay-accelerating factors of the system which clear complement components from host cells that have been inadvertently targeted by the system.

Pathogens target and subvert the complement system by degrading or binding complement components to prevent activation of the pathway. Given the highly centralized role of the C3 and C5 convertase complexes, it is not surprising that they are the major targets of many bacterial proteases which inactivate the system. In particular, the $\mathrm{C} 3$ protein and its activated form, $\mathrm{C} 3 \mathrm{~b}$, is an integral component of the C5 convertase complex whichever pathway of activation has been engaged. Thus, a number of bacterial proteases, such as the SpeB cysteine protease (streptopain) from the group A streptococci [42, 43], cleave either $\mathrm{C} 3$ and thus inactivate or prevent the formation of the C5 convertase complex. This has the dual effects of preventing the formation of the membrane attack complex and the most pro-inflammatory mediator, C5a. The ultimate effect of the cleavage is to prevent coating of the bacteria with $\mathrm{C} 3 \mathrm{~b}$, which in turn prevents or reduces important mechanisms such as opsonization and phagocytosis by neutrophils. The SpeB protease also cleaves properdin, which stabilizes the formation of the $\mathrm{C} 5$ convertase complex formed during alternative activation pathway of complement [44]. This has the cumulative ef- 
fect making the bacterium more resistant to opsonophagocytosis by neutrophils. Interestingly, the group A and group B streptococci also produce a C5a peptidase of the subtilisin family (S8) of serine proteases, which cleaves C5a near its N-terminus and thus affects the attraction of neutrophils to the site of infection, thereby inhibiting the clearance and phagocytosis of the organism [45]. An interesting mechanism used by $S$. aureus with regard to $\mathrm{C} 3$ degradation is binding of the host protein by clumping factor A produced by the organism, which enhances the degradation of C3 by factor I, a protease of the alternative pathway that regulates complement activation [46]. This enhancement of the degradation of $\mathrm{C} 3$ prevents phagocytosis of the bacterium. The PgtE protease of S. enterica degrades C3b, C4b and C5 and thus drastically affects convertase complex activity [47] and protects the bacterium from complement during its transient extracellular phase prior to entry of the host cells. The gelatinase of Enterococcus faecalis has been shown to inactivate complement by degrading $\mathrm{C} 3$ and thus contributes to the pathogenicity of this bacterium [48].

The gingipains from the periodontal pathogen, $P$. gingivalis, have been shown to have complex, 'biphasic' effects on the complement system [49]. The bacterium is resistant to complement, most likely due to the presence of a surface anionic polysaccharide [50], and the gingipains, particularly the arginine-specific enzymes, degrade C3, C4 and C5 [49]. Interestingly, at low concentrations, the gingipains activated these proteins by cleaving at their correct cleavage positions required for subsequent activation of the system, but at higher concentrations the enzymes degraded the complement proteins such that they were inactivated. This suggests that early infections by $P$. gingivalis (correlated with lower gingipain concentrations) may actually stimulate complement activation to cause an inflammatory state that is advantageous to the bacterium in terms of supplying it with nutrients, while later infections with high number of bacteria would be likely to degrade vital complement components to inactivate the system. In addition, $P$. gingivalis is able to capture the human complement inhibitor, C4b-binding protein (C4BP) via the surface-exposed RgpA moiety. Immobilization of C4BP on the bacterial surface further contributes to their serum resistance of $P$. gingivalis. Interestingly, clinical isolates bound more C4BP than laboratory strains tested [51]. Collectively, gingipains appeared to be a very significant virulence factor, not only destroying complement due to proteolytic degradation, but also inhibiting complement activa- tion due to their ability to bind complement inhibitor C4BP on their surface. It should also be noted that the lysine-specific gingipain is additionally capable of degrading the $\mathrm{C} 5$ a receptor, thus inactivating signals derived from activation of complement.

The StcE cysteine protease of the E. coli O157:H7 strain uses a unique mechanism to prevent complement activation via the classical pathway on its surface and the surface of adjacent host cells. The protease binds and cleaves the serpin, $\mathrm{C} 1$ inhibitor, the major regulator of the proteases of the initiating $\mathrm{Cl}$ complex of the classical pathway, at the N-terminus of the host protein [52]. The binding of the inhibitor at the bacterial and cellular surfaces inhibits the complement proteases, preventing complement activation and thus inflammation. Cleavage of the N-terminus of the serpin might liberate its anti-inflammatory $\mathrm{N}$ terminal domain, but this is yet to be shown.

\section{Inactivation of Bactericidal Peptides}

Antimicrobial host defense peptides are widely distributed in animals and plants. They are extremely divergent with respect to their structure and constitute the most ancient, yet efficient chemical weapon of host defense. In higher animals, AMPs show a broad spectrum of activities related to both innate and acquired immunity, including immunostimulatory and immunomodulatory functions, but their primary role is to directly kill invading microorganisms [53]. This is mostly done by disruption of bacterial cell membrane integrity. Defensins and cathelicidins are the major and best characterized groups of AMPs: their function in vivo is reinforced by AMPs derived from chemokines [54], complement [14, 55, 56], hemoglobin (hemocidins) [57], kininogen [58], heparin-binding proteins $[59,60]$, growth factors [61] and many other peptides and proteins (for a more complete list and references, see Radek and Gallo [62]). Nevertheless, despite the prevalence of these effective chemical agents, we are still susceptible to infection diseases. During billions of years of co-evolution with multicellular eukaryotic organisms, successful pathogens have developed a variety of redundant means to bypass or even take advantage of AMPs [63]. Despite the fact that AMPs are relatively resistant to proteolytic degradation, several pathogenic bacteria use proteases to cleave and inactivate AMPs.

The human cathelicidin LL-37 is the direct target for degradation by SufA, a novel subtilisin-like serine protease of Finegoldia magna (formerly Peptostreptococcus 
magnus) [64], streptopain of $S$. pyogenes, elastase of $P$. aeruginosa, gelatinase of $E$. faecalis and the $50-\mathrm{kDa}$ metalloprotease (ZapA) of Proteus mirabilis [65]. In each case, proteolysis led to loss of LL-37 binding to bacteria and, consequently, abolished bactericidal activity. Inactivation of LL-37 may be related to the colonization of chronic ulcers, rich in AMPs, by $P$. aeruginosa, E. faeca$l i s$ and $P$. mirabilis. Several lines of evidence argue for this conclusion, at least in the case of $P$. aeruginosa. Firstly, elastase production by $P$. aeruginosa rendered the bacterium totally resistant to the action of LL-37 during growth in human wound fluid ex vivo, in stark contrast to an elastase-deficient strain, for which growth was strongly limited. Secondly, LL-37 was degraded in chronic wound fluid collected from $P$. aeruginosa-infected ulcers, but not in acute, sterile wound fluid. Thirdly, the elastase can degrade the cathelicidin proprotein (hCAP18) in neutrophil extracts. Finally, these ex vivo observations correlate well with clinical findings showing that chronic venous ulcers are devoid of LL-37 and contain low levels of hCAP18 [65]. The persistence of protease-producing P. aeruginosa, $P$. mirabilis and E. faecalis in chronic ulcers and wounds can be further enhanced by proteolytic degradation of dermatan sulfatecontaining proteoglycans, such as decorin. The negatively charged dermatan sulfate released in this process binds to neutrophil-derived cationic $\alpha$-defensin and totally abrogates the bactericidal activity of this AMP [66]. Also, the shedding of ectodomains of the heparin sulfate proteoglycan, syndecan-1, from various host cells by the LasA protease may additionally contribute to $P$. aeruginosa virulence [67] through complexing and inactivation of cationic AMPs.

The ZapA metalloprotease of P. mirabilis is an essential virulence factor in urinary tract infections. In addition to degradation of LL-37, this enzyme also cleaves and inactivates human $\beta$-defensin (hBD1) [68]. Since hBD1 (and hBD2) is active in the human urinary tract, its cleavage by ZapA may contribute to colonization of this tract by $P$. mirabilis. However, both wild-type and ZapA-deficient mutants are resistant to different AMPs, including hBD1, hBD2, LL37 and protegrin, indicating that mechanisms other than proteolytic degradation might influence the resistance of $P$. mirabilis to AMPs. An analogous scenario exists with respect to the resistance of $P$. gingivalis, the major periodontopathogen, to the bactericidal activity of AMPs. The gingipains efficiently degrade several different AMPs, including LL-37, dermaseptin (an AMP from the skin of tree frogs) and histatin 5, as well as cecropin B and brevinin. Addition-

Corruption of Innate Immunity by

Bacterial Proteases ally, proteolytic activity released by $P$. gingivalis into growth media efficiently degrades physiologically relevant AMPs, such as $\alpha$-defensin (HNP-1), hBD-1, hBD-2 and hBD3 [69]. However, these activities do not seem to contribute to resistance of the bacterium to the action of the AMPs [70] and how this activity adds to the resistance of $P$. gingivalis to AMPs still needs to be tested. In this regard, it should be noted that $P$. gingivalis occurs in close association with many other microorganisms in the biofilm of the dental plaque, upon which the bacterium is metabolically dependent. In this crowded environment, the proteolytic degradation of AMPs by P. gingivalis proteases may yield protection to its commensal partners that are sensitive to AMPs, such as Fusibacterium nucleatum. Additional protection can also be yielded by disturbing the balance between endogenous proteases and their inhibitors. To this end, inactivation of cystatins by gingipains and the proteases of Prevotella intermedia may release host cathepsins from their tight control by cystatins, ultimately leading to the local proteolytic depletion of AMP activity [71]. Indeed, acquired local deficiency in LL-37 due to proteolytic degradation seems to be a supporting factor in pathogenesis of severe cases of periodontitis [72]. In this context, it is important to note that LL-37 is essential for homeostasis in the periodontium, since genetic deficiencies in this cathelicidin are linked to the development of severe cases of aggressive periodontitis.

Cathelicidins are important components of innate host immunity that confer defense against Gram-positive bacterial infection in the skin. Therefore, it is not surprising that 2 major skin pathogens, $S$. aureus and $S$. pyogenes, produce proteases degrading human cathelicidins. Aureolysin of the former bacterium cleaves and inactivates LL-37 in a concentration- and time-dependent manner, and an inverse correlation was found between the level of aureolysin production by $S$. aureus strains and their susceptibility to LL-37 [73]. Interestingly, both $S$. aureus and $S$. epidermidis can sense the presence of dermicidin, an important AMP expressed in the skin, and react to it by raising their extracellular proteolytic activity, leading to proteolytic degradation and resistance to dermcidin [74]. The resistance of $S$. aureus is further enforced by staphylokinase, which induces the secretion of defensins from neutrophils only to neutralize their bactericidal effect and facilitate the infection process [75]. An example of how this operates is where LL-37 binds directly to staphylokinase, potentiating staphylokinase-dependent plasminogen activation and fibrinolysis, which may lead to enhanced bacterial dis- 
semination and invasive infection [76]. Finally, as in the case of the periodontopathogens, cysteine proteases produced by $S$. aureus (staphopains) are able to inactivate cystatins [77], thus potentially enhancing the local activity of cathepsins, which in turn can inactivate AMPs.

Streptopain (SpeB), the major protease produced by $S$. pyogenes, is involved in an interesting system that the pathogen has evolved to protect its own cell surface-located virulence factors and simultaneously promote the degradation of LL-37. Using a surface-expressed protein, GRAB, $S$. pyogenes coats itself with $\alpha_{2}$-macroglobulin $\left(\alpha_{2} \mathrm{M}\right)$, a major human plasma proteinase inhibitor. The $\alpha_{2} \mathrm{M}$ thus retained on the surface inhibits proteolysis by trapping streptopain that, however, still remains proteolytically active against smaller peptides, including LL-37, that can penetrate the $\alpha_{2} \mathrm{M}$-streptopain complex. As a consequence, $S$. pyogenes is well protected against killing by LL-37 [78]. Importantly, recent findings indicate that, indeed, the streptopain-mediated inactivation of LL-37 on the streptococcal surface represents a bacterial resistance mechanism at infected sites in patients with severe $S$. pyogenes soft tissue infections [79].

The omptins located on the outer membrane of Gramnegative bacteria are also able to degrade and inactivate AMPs. Thus far it has been shown that OmpP and OmpT of $E$. coli efficiently degrade protamione, which promotes resistance to this particular AMP [80]. Conversely, the S. enterica omptin, PgtE, conferred resistance to $\alpha$-helical cationic AMPs, including LL-34, but not to protegrin or HNP-1, the $\beta$-sheet AMPs [81]. This indicates that different omptins may have specificity directed against various AMPs. PgtE expression is regulated by $\mathrm{PhoP} / \mathrm{PhoQ}$ sensing of sublethal concentrations of cationic AMPs and, through AMP degradation, the protease contributes to promotion of bacterial survival and resistance against host innate immune defense mechanisms [82].

\section{PAR Activation/Inactivation by Bacterial Proteases}

PARs are G protein-coupled, 7 transmembrane domain molecules that are activated by proteases. Cleavage within the extracellular domain of the receptors results in the liberation of a new $\mathrm{N}$-terminal sequence which interacts with the extracellular loops of the receptor as a tethered ligand, causing intracellular signaling that has a variety of outcomes depending on the receptor activated, the type of cell/tissue and the status of the cell. Of the 4 human members of the family, PAR-1, PAR-3 and PAR-4 are activated physiologically by the action of thrombin, while PAR-2 is activated by many different proteases. PAR-2 activation in particular has frequently been associated with pro-inflammatory responses.

The arginine-specific gingipains from $P$. gingivalis were shown to activate PAR-2 on neutrophils [83] and epithelial cells [84], with activation in the latter context causing the production of pro-inflammatory IL-6. The arginine-specific gingipains were also shown to activate PAR-1 and PAR-4 on human platelets and thus cause platelet activation and aggregation [85]. Subsequent to these initial findings, a number of different studies have amplified the original data and recently PAR-2 null mice were shown to be protected against periodontal disease, suggesting that this receptor does indeed play a pivotal role in the pathogenesis of this disease [86].

Following these findings in the context of periodontal disease, it has been shown that a secreted protease from P. aeruginosa, LepA, is able to activate PAR-1, PAR-2 and PAR- 4 and thus activates a NF- $\kappa$ B pathway [87]. Interestingly, the elastolytic metalloprotease from the same bacterium, LasB, was shown to degrade the extracellular domain of PAR-2 and thus inactivate the receptor [88], suggesting that these proteases from the same organism might antagonize each others' effects. Recently, serralysin from Serratia marcescens was shown to activate PAR2 in human lung carcinoma and HeLa cells, with subsequent activation of pro-inflammatory signaling pathways [89]. Finally, Helicobacter pylori has been shown to be able to activate PAR-2 on gastric epithelial cells and although the proteases from the bacterium carrying out the activity have not been characterized, it appeared that a serine protease was most likely involved [90]. The activation resulted in increased production of pro-inflammatory IL- 8 by the gastric cells.

The above results and those summarized in table 2 indicate that signaling through PARs acts as a system to detect extracellular proteolysis and thus allows cells to act to protect themselves and/or alert general defense systems.

\section{Disruption of Communication Networks by Degradation of Cytokines and Their Receptors}

Cells of the innate and acquired immune systems communicate via chemical signals constituted by small proteins generally referred to as cytokines. Cytokines, released by sentry cells sensing pathogens and in response 
Table 2. Bacterial-derived proteases affecting PARs

\begin{tabular}{|c|c|c|c|}
\hline \multicolumn{4}{|l|}{ P. gingivalis } \\
\hline RgpB & PAR-2/human neutrophils & $\begin{array}{l}\text { increase in the intracellular calcium concentration, } \\
\text { pro-inflammatory activation }\end{array}$ & 85 \\
\hline RgpB and HRgpA & PAR-1 and PAR-2 /oral epithelial cell line (KB) & IL-6 secretion & 86 \\
\hline Gingipains & PAR-2/human gingival epithelial cells & induction of hBD-2 expression & 115 \\
\hline RgpB & PAR-2/dental pulp cells & neuropeptide release, inflammation & 116 \\
\hline RgpA & PAR/endotelial cells & Weibel-Palade body exocytosis & 117 \\
\hline RgpA & PAR/resting T cells & induction of CD69 and CD25, T cell activation & 118 \\
\hline Gingipians & $\begin{array}{l}\text { PAR-1, PAR-2, and PAR-3/human monocytic cell } \\
\text { line (THP-1 cells) }\end{array}$ & $\begin{array}{l}\text { stimulated secretion of cytokines (IL- } 6 \text {, IL- } 8 \text {, } \\
\text { and MCP-1) through the activation of PARs } \\
\text { with synergistic effects by PAMPs }\end{array}$ & 122 \\
\hline Gingipains & PAR-1 and PAR-2/human oral epithelial cells & gingipain-dependent effect on IL-8 expression & 123 \\
\hline \multicolumn{4}{|l|}{ P. aeruginosa } \\
\hline LasA (elastase) & PAR-2/respiratory epithelial cells & $\begin{array}{l}\text { disarm PAR- } 2 \text { in regard to any further activating } \\
\text { proteolysis by activating protease }\end{array}$ & 90 \\
\hline LepA & $\begin{array}{l}\text { PAR-1, PAR-2 and PAR-3/PAR transfected COS-7 } \\
\text { cells and human bronchiole epithelial cell line }\end{array}$ & $\begin{array}{l}\text { activate NF-кB-driven promoter, induce IL-8 } \\
\text { production through PAR-2 in EBC-1 cells }\end{array}$ & 89 \\
\hline
\end{tabular}

PAMPS $=$ Pathogen-associated molecular patterns.

to components of damaged tissue, are essential for mounting the inflammatory reaction, as well as its regulation and resolution. Therefore, the interaction between bacteria and cytokine networks is an important theme in microbial pathogenicity. Disturbance of this communication network has the potential to profoundly affect the pathological outcome of infectious diseases. One mode of disruption of cytokine signaling can occur through proteolytic modification of these molecules and their receptors on cell surfaces. Perhaps not surprisingly, cytokines and their receptors were found to be susceptible to degradation by a large array of bacterial-derived proteases (table 1). Without exception, cytokine and receptor cleav- age is executed by promiscuous proteases that also target several other pathologically relevant proteins/peptides of the innate immune system as it is best documented for gingipains, cysteine proteases produced by $P$. gingivalis [91]. In this case, the system is further complicated by the ability of gingipains to directly stimulate cytokine release by immune cells [92]. Moreover, it should be noted that due to the complex and redundant meshwork of cytokine functions, it is difficult to extrapolate in vitro findings to the situation in infected tissues and therefore the overall pathological effects of the proteolysis of these molecules. 


\section{Effect on Chemokines}

Chemokines are a distinct, large superfamily of cytokines encompassing small $(8-15 \mathrm{kDa})$ structurally related proteins consisting of an $\mathrm{N}$-terminal region followed and connected via cysteine bonds to its $\beta$-sheet core and a C-terminal $\alpha$-helix. All possess chemotactic activity for immune cells. To date, at least 46 chemokines which signal through 18 functional $G$ protein-coupled receptors have been identified in humans. According to their physiological role, they are described as either inflammatory or homeostatic chemokines. The function of inflammatory chemokines is to recruit leukocytes for host defense. Modulation of chemokine activity by proteolytic processing at both $\mathrm{N}$ - and C-termini is a common feature and the coordinated truncation of inflammatory cytokines by host matrix metalloproteases is critical for both influx and termination of neutrophil recruitment in acute inflammation $[93,94]$.

The N-terminal sequence of chemokines preceding the first conservative cysteine residue is exposed and conformationally disordered; therefore, these molecules are easily proteolytically processed at the $\mathrm{N}$-terminus. In the case of several CXC inflammatory chemokines, including CXCL8 (IL-8), the main human neutrophil-attracting chemokine, such cleavage results in amplification of their activity, which is thought to be essential for inflammatory influx of neutrophils. This capability of activating IL- 8 has apparently been usurped by the gingipains of $P$. gingivalis. Soluble RgpA, RgpB and Kgp efficiently truncate IL- 8 at the N-terminus enhancing its activity [95] and this correlates well with the massive infiltration of neutrophils into periodontitis sites. Interestingly, the same enzymes, when associated with bacterial outer membrane blebs (vesicles), instantly degrade this chemokine at multiple points. This division of enhancing and inactivating activity between soluble and membranebound gingipains is likely to result in the compartmentalization of pro- and anti-inflammatory reactions to distal and proximal positions from the bacterial plaque, respectively, which may explain why there is no elimination of infection despite the massive neutrophil accumulation at periodontitis sites [95].

The alkaline protease and elastase of $P$. aeruginosa efficiently degraded human RANTES, monocyte chemotactic protein-1 and epithelial neutrophil-activating protein-78, but not IL-8. Degradation was accompanied by a loss of chemotactic activity. It was suggested that the chemokine degradation could alter the relative amounts of critical immunomodulatory cytokines in the airway and, thus, could contribute to the pathophysiology observed in $P$. aeruginosa-associated lung disease [96]. However, the overall importance of this observation has not been verified experimentally.

Similarly to $Y$. pestis infections (see Escaping Host Defenses by Manipulating Fibrinolysis), lesions of lethal necrotizing fasciitis caused by $S$. pyogenes are characterized by an absence of neutrophils at the site of bacterial growth. In this case, however, the paucity of neutrophils in the necrotizing fasciitis lesions was correlated with limited proteolysis of IL- 8 in its C-terminal domain by the streptococcal cell envelope protease SlyCEP [97]. Follow-up studies have identified the gene encoding SlyCEP and found that the protease shares an extensive homology to the well-known C5a peptidase (ScpA). In addition, it was shown that IL-8 SlyCEP cleaves the C-terminal domain of the murine CXC chemokines, $\mathrm{KC}$ and MIP-2, and is an essential factor for S. pyogenes pathogenicity in the murine model of infection. The IL- $8 \mathrm{C}-$ terminal domain cleavage by SlyCEP is necessary and sufficient to reduce IL-8-dependent neutrophil endothelial transmigration and promotes resistance to neutrophil killing [98]. Furthermore, SlyCEP was also shown to cleave granulocyte chemotactic protein 2 and growth-related oncogene- $\alpha, 2$ potent chemokines that are abundant in human tonsils. Cleavage of these 2 chemokines by SpyCEP abrogated their ability to prime neutrophils for activation, detrimentally altering the innate immune response. A functional homologue of SlyCEP that cleaves IL-8, promoting neutrophil resistance, was found in the zoonotic pathogen, Streptococcus iniae [98]. Taken together, these data suggest that SlyCEP is a very efficient weapon used by streptococci to impair bacteria clearance by neutrophils. To date, no substrates other than chemokines have been identified for SlyCEP, suggesting that the enzyme has unique activity custommade for cleavage of the C-terminal domain of chemokines. Cleavage at this site deprives the chemokine of its ability to interact with glycosaminoglycans that are essential for surface presentation of chemokines by venular endothelial cells, which in turn is a prerequisite for neutrophil transcytosis. In some respects, chemokine cleavage by SlyCEP is an interesting example of functional mimicry, since it resembles the use of MMP12 by macrophages to terminate polymorphonuclear leukocytes influx by proteolytic inactivation of inflammatory chemokines [94]. 


\section{Disarming Professional Phagocytes}

Neutrophils, macrophages, monocytes and natural killer cells constitute the cellular branch of innate immunity. As in the case of other immunity barriers, this can also be breached by specialized pathogens. The best described pathway depends on injecting phagocytes with effectors that disable their antibacterial functions or eliminate the cells. If proteases are used in this process, they are usually specialized just to perform their job of silencing the antibacterial functions of phagocytes (see Bacterial Proteases Targeting and Manipulating Intracellular Inflammatory Signaling Pathways of Innate Immunity). The antibacterial potential of phagocytes is also dampened by general proteases. SpeB can cause mitochondrial damage in polymorphonuclear leukocytes cells, preventing immune clearance of $S$. pyogenes at an early infectious stage [99]. Furthermore, SpeB was shown to selectively cleave antigen-bound antibodies at the hinge region. Simultaneously, IgGs captured via their Fc region by immunoglobulin-binding proteins on the surface of $S$. pyogenes were protected from cleavage. Collectively, this strategy facilitates escape from opsonophagocytosis, while not interfering with the formation of a host-like coat by IgG molecules immobilized on the surface via their Fc region. These findings correlate with the observation that genetic inactivation of SpeB decreased the resistance of the mutant bacterium to phagocytosis and impaired its subsequent dissemination to organs. Protection against opsonophagocytosis is further enhanced by complement inactivation by SpeB and IgG splicing by IdeS, a cysteine protease with a unique specificity for the IgG hinge region [100]. Interestingly, cystatin C, a cysteine protease inhibitor, acts as cofactor that accelerates IgG cleavage by IdeS. This is a unique example of the 'hijacking' of a host protease inhibitor by a bacterial protease to increase its activity [101]. In vivo SpeB apparently contributes to the intracellular survival of $S$. pyogenes in macrophages during acute invasive infections [102]. Similarly, aureolysin contributes to the intracellular persistence of $S$. aureus after phagocytosis by macrophages [103].

Immune cell functions can also be disabled or diminished by proteolytic modification of specific receptors on their surface. Apart from the cleavage of cytokine receptors (see above), this effect is exemplified by inactivation of the C5a receptor, degradation of CD14 [104], shedding of CD44 [105] and syndecan-1 [69, 106, 107], and cleavage of the urokinase-type plasminogen activator receptor [108] by bacterial proteases. Potentially, any of these cleavages may have significant effects on innate immunity.

Corruption of Innate Immunity by Bacterial Proteases
In this issue, we have described a novel and specific mechanism of disabling and eliminating blood phagocytes by $\mathrm{SspB}$, a cysteine protease secreted by $S$. aureus. SspB selectively cleaves CD11b on phagocytes, which rapidly acquire features of cell death and become subjects of extensive, nonphlogistic clearance by macrophages [109]. Similar effects on neutrophils were exerted by the proteases of $P$. gingivalis, where gingipains sensitized healthy neutrophils for uptake by macrophages, whereas endogenous proteinases were unable to elicit this effect. This stimulation was apparently induced by the combined effect of proteolytic cleavage of an antiphagocytic signal (CD31) and the generation of a novel 'eat-me' signal on the neutrophil surface [110]. In both cases, the action of the bacterial proteases on the phagocytes would be likely to affect the local inflammatory process to the benefit of the invading pathogens.

\section{Scavenging of Iron with the Aid of Bacterial Proteases}

Iron limitation by vertebrates is one of the most important instruments of innate immunity to impair microbial growth. Due to a large number of iron- and haem-sequestering proteins, the level of free iron in human body fluids is at the femtomolar concentration, much lower than the requirements for growth by the majority of microorganisms. As a countermeasure to iron limitation, bacteria have developed many different systems to acquire iron or haem. To date, the use of proteases in iron/haem acquisition was characterized in E. coli and P. gingivalis. The hemoglobin protease of $E$. coli interacts with hemoglobin, degrades it and subsequently binds the released haem, which is then shared with Bacteroides fragilis [111]. Both bacteria remain in a symbiotic relation causing intraabdominal abscesses. For P. gingivalis, methemoglobin is efficiently degraded by the Lys-specific gingipain (Kgp) [112], while the sequential action of Arg-specific gingipains and Kgp is needed to break down oxyhemoglobin [113]. The haem-containing pigment thus generated is deposited in the $P$. gingivalis cell envelope, causing black pigmentation of the bacterium cultured on blood agar.

\section{Concluding Statements}

The innate immune system has clearly developed a legion of different strategies to control bacteria and thus prevent associated disease. Just as clear, however, is that 
bacteria have taken advantage of these many strategies to turn the immunological strengths into weaknesses and thus gain themselves an evolutionary advantage. Bacterial proteases have merged as key molecules that are able to affect the molecules and cells of the innate immune system to bacterial advantage, using an astonishing array of ingenious mechanisms to achieve the desired outcome for the microorganism. Given that there are thousands of different species of bacteria, each producing many proteases, it is likely that many more fascinating, yet deadly mechanisms will be discovered. It is vital that these are characterized in order to develop effective strategies for the control of bacterial infections.

\section{Acknowledgements}

This work was supported in part by grants from the Ministry of Science and Higher Education, Warsaw, Poland (1642/B/ P01/2008/35), the National Institutes of Health (grant DE 09761; both to J.P.) and institutional funds (BW9 and DS9) from the Faculty of Biochemistry, Biophysics and Biotechnology, Jagiellonian University, Krakow, Poland.

\section{References}

1 Esmon CT: Interactions between the innate immune and blood coagulation systems. Trends Immunol 2004;25:536-542

-2 Frick IM, Björck L, Herwald H: The dual role of the contact system in bacterial infectious disease. Thromb Haemost 2007;98:497502.

-3 Shpacovitch V, Feld M, Bunnett NW, Steinhoff M: Protease-activated receptors: novel PARtners in innate immunity. Trends Immunol 2007;28:541-550.

4 Hollenberg MD, Oikonomopoulou K, Hansen KK, Saifeddine M, Ramachandran R, Diamandis EP: Kallikreins and proteinasemediated signaling: proteinase-activated receptors (PARs) and the pathophysiology of inflammatory diseases and cancer. Biol Chem 2008;389:643-651.

5 Ramsay AJ, Reid JC, Adams MN, Samaratunga H, Dong Y, Clements JA, Hooper JD: Prostatic trypsin-like kallikrein-related peptidases (KLKs) and other prostate-expressed tryptic proteinases as regulators of signalling via proteinase-activated receptors (PARs). Biol Chem 2008;389:653-668.

6 Hansen KK, Oikonomopoulou K, Baruch A, Ramachandran R, Beck P, Diamandis EP, Hollenberg MD: Proteinases as hormones: targets and mechanisms for proteolytic signaling. Biol Chem 2008;389:971-982.

7 Ulanova M, Gravelle S, Barnes R: The role of epithelial receptors in recognition of pulmonary pathogens. J Innate Immun 2009;1:4 17.

8 Bengtson SH, Sanden C., Morgelin M, Marx PF, Olin AI, Leed-Lundberg LMF, Meijers JCM, Herwald H: Activation of TAFI on the surface of Streptococcus pyogenes evokes inflammatory reactions by modulating the kallikrein/kinin system. J Innate Immun 2009;1:18-28.
9 Bengtson SH, Eddleston J, Mörgelin M, 17 Sun H, Ringdahl U, Homeister JW, Fay WP, Zuraw BL, Herwald H: Regulation of kinin $\mathrm{B}(2)$ receptors by bradykinin in human lung cells. Biol Chem 2008, E-pub ahead of print. 10 Imamura T, Tanase S, Szmyd G, Kozik A, Travis J, Potempa J: Induction of vascular leakage through release of bradykinin and a novel kinin by cysteine proteinases from Staphylococcus aureus. J Exp Med 2005;201: 1669-1676.

11 Imamura T, Potempa J, Pike RN, Travis J: Dependence of vascular permeability enhancement on cysteine proteinases in vesicles of Porphyromonas gingivalis. Infect Immun 1995;63:1999-2003.

12 Hu SW, Huang CH, Huang HC, Lai YY, Lin YY: Transvascular dissemination of Porphyromonas gingivalis from a sequestered site is dependent upon activation of the kallikrein/ kinin pathway. J Periodontal Res 2006;41: 200-207.

13 Sakata Y, Akaike T, Suga M, Ijiri S, Ando M, Maeda $\mathrm{H}$ : Bradykinin generation triggered by Pseudomonas proteases facilitates invasion of the systemic circulation by Pseudomonas aeruginosa. Microbiol Immunol 1996;40:415-423.

14 Frick IM, Akesson P, Herwald H, Mörgelin M, Malmsten M, Nägler DK, Björck L: The contact system - a novel branch of innate immunity generating antibacterial peptides. EMBO J 2006;25:5569-5578.

15 Bergmann S, Hammerschmidt S: Fibrinolysis and host response in bacterial infections. Thromb Haemost 2007;98:512-520.

16 Sanderson-Smith ML, Dinkla K, Cole JN, Cork AJ, Maamary PG, McArthur JD, Chhatwal GS, Walker MJ: M protein-mediated plasminogen binding is essential for the virulence of an invasive Streptococcus pyogenes isolate. FASEB J 2008;22:2715-2722. Engleberg NC, Yang AY, Rozek LS, Wang X, Sjöbring U, Ginsburg D: Plasminogen is a critical host pathogenicity factor for group A streptococcal infection. Science 2004;305: 1283-1286.

18 Coleman JL, Gebbia JA, Piesman J, Degen JL, Bugge TH, Benach JL: Plasminogen is required for efficient dissemination of $B$. burgdorferi in ticks and for enhancement of spirochetemia in mice. Cell 1997;89:1111-1119.

-19 Parry MA, Fernandez-Catalan C, Bergner A, Huber R, Hopfner KP, Schlott B, Gührs KH, Bode W: The ternary microplasmin-staphylokinase-microplasmin complex is a proteinase-cofactor-substrate complex in action. Nat Struct Biol 1998;5:917-923.

20 Ward PN, Abu-Median AB, Leigh JA: Structural consideration of the formation of the activation complex between the staphylokinase-like streptococcal plasminogen activator Pad A and bovine plasminogen. J Mol Biol 2008;381:734-747.

21 Hritonenko V, Stathopoulos C: Omptin proteins: an expanding family of outer membrane proteases in Gram-negative Enterobacteriaceae. Mol Membr Biol 2007;24: 395-406.

22 Kukkonen M, Suomalainen M, Kyllönen P, Lähteenmäki K, Lång H, Virkola R, Helander IM, Holst O, Korhonen TK: Lack of Oantigen is essential for plasminogen activation by Yersinia pestis and Salmonella enterica. Mol Microbiol 2004;51:215-225.

-23 Sodeinde OA, Subrahmanyam YV, Stark K, Quan T, Bao Y, Goguen JD: A surface protease and the invasive character of plague. Science 1992;258:1004-1007.

24 Sebbane F, Jarrett CO, Gardner D, Long D, Hinnebusch BJ: Role of the Yersinia pestis plasminogen activator in the incidence of distinct septicemic and bubonic forms of fleaborne plague. Proc Natl Acad Sci USA 2006; 103:5526-5530. 
-25 Lathem WW, Price PA, Miller VL, Goldman WE: A plasminogen-activating protease specifically controls the development of primary pneumonic plague. Science 2007;315:509513.

26 Degen JL, Bugge TH, Goguen JD: Fibrin and fibrinolysis in infection and host defense. J Thromb Haemost 2007;5(suppl 1):24-31.

-27 Rytkönen A, Holden DW: Bacterial interference of ubiquitination and deubiquitination. Cell Host Microbe 2007;1:13-22.

- 28 Orth K, Xu Z, Mudgett MB, Bao ZQ, Palmer LE, Bliska JB, Mangel WF, Staskawicz B, Dixon JE: Disruption of signaling by Yersinia effector YopJ, a ubiquitin-like protein protease. Science 2000;290:1594-1597.

29 Zhou H, Monack DM, Kayagaki N, Wertz I, Yin J, Wolf B, Dixit VM: Yersinia virulence factor YopJ acts as a deubiquitinase to inhibit NF-кB activation. J Exp Med 2005;202: 1327-1332.

- 30 Thiefes A, Wolf A, Doerrie A, Grassl GA, Matsumoto K, Autenrieth I, Bohn E, Sakurai H, Niedenthal R, Resch K, Kracht M: The Yersinia enterocolitica effector YopP inhibits host cell signalling by inactivating the protein kinase TAK1 in the IL-1 signalling pathway. EMBO Rep 2006;7:838-844.

- 31 Haase R, Richter K, Pfaffinger G, Courtois G, Ruckdeschel K: Yersinia outer protein $P$ suppresses TGF- $\beta$-activated kinase-1 activity to impair innate immune signaling in Yersinia enterocolitica-infected cells. J Immunol 2005;175:8209-8217.

- 32 Sweet CR, Conlon J, Golenbock DT, Goguen J, Silverman N: YopJ targets TRAF proteins to inhibit TLR-mediated NF- $\kappa \mathrm{B}, \mathrm{MAPK}$ and IRF3 signal transduction. Cell Microbiol 2007;9:2700-2715.

33 Mukherjee S, Keitany G, Li Y, Wang Y, Ball HL, Goldsmith EJ, Orth K: Yersinia YopJ acetylates and inhibits kinase activation by blocking phosphorylation. Science 2006;312: 1211-1214.

- 34 Trosky JE, Liverman AD, Orth K: Yersinia outer proteins: Yops. Cell Microbiol 2008; 10: 557-565.

- 35 Rytkönen A, Poh J, Garmendia J, Boyle C, Thompson A, Liu M, Freemont P, Hinton JC, Holden DW: SseL, a Salmonella deubiquitinase required for macrophage killing and virulence. Proc Natl Acad Sci USA 2007;104: 3502-3507.

- 36 Le Negrate G, Faustin B, Welsh K, Loeffler M, Krajewska M, Hasegawa P, Mukherjee S, Orth K, Krajewski S, Godzik A, Guiney DG, Reed JC: Salmonella secreted factor L deubiquitinase of Salmonella typhimurium inhibits NF- $\kappa \mathrm{B}$, suppresses IкB $\alpha$ ubiquitination and modulates innate immune responses. J Immunol 2008; 180:5045-5056.

- 37 Misaghi S, Balsara ZR, Catic A, Spooner E, Ploegh HL, Starnbach MN: Chlamydia trachomatis-derived deubiquitinating enzymes in mammalian cells during infection. Mol Microbiol 2006;61:142-150.
Catic A, Misaghi S, Korbel GA, Ploegh HL: by E. coli. PLoS One 2007;2:e381.

39 Chosed R, Tomchick DR, Brautigam CA, Mukherjee S, Negi VS, Machius M, Orth K: Structural analysis of Xanthomonas XopD provides insights into substrate specificity of ubiquitin-like protein proteases. J Biol Chem 2007;282:6773-6782.

40 Shao F, Merritt PM, Bao Z, Innes RW, Dixon JE: A Yersinia effector and a Pseudomonas avirulence protein define a family of cysteine proteases functioning in bacterial pathogenesis. Cell 2002;109:575-588.

41 Park JM, Greten FR, Li ZW, Karin M: Macrophage apoptosis by anthrax lethal factor through p38 MAP kinase inhibition. Science 2002;297:2048-2051.

42 Kuo CF, Lin YS, Chuang WJ, Wu JJ, Tsao N: Degradation of complement 3 by streptococcal pyrogenic exotoxin B inhibits complement activation and neutrophil opsonophagocytosis. Infect Immun 2008;76: 1163-1169.

43 Terao Y, Mori Y, Yamaguchi M, Shimizu Y, Ooe K, Hamada S, Kawabata S: Group A streptococcal cysteine protease degrades C3 (C3b) and contributes to evasion of innate immunity. J Biol Chem 2008;283:62536260.

44 Tsao N, Tsai WH, Lin YS, Chuang WJ, Wang $\mathrm{CH}$, Kuo CF: Streptococcal pyrogenic exotoxin $\mathrm{B}$ cleaves properdin and inhibits complement-mediated opsonophagocytosis. Biochem Biophys Res Commun 2006;339: 779-784.

45 Ji Y, McLandsborough L, Kondagunta A, Cleary PP: C5a peptidase alters clearance and trafficking of group A streptococci by infected mice. Infect Immun 1996;64:503510.

46 Hair PS, Ward MD, Semmes OJ, Foster TJ, Cunnion KM: Staphylococcus aureus clumping factor $\mathrm{A}$ binds to complement regulator factor I and increases factor I cleavage of C3b. J Infect Dis 2008;198:125-133.

47 Ramu P, Tanskanen R, Holmberg M, Lähteenmäki K, Korhonen TK, Meri S: The surface protease PgtE of Salmonella enterica affects complement activity by proteolytically cleaving C3b, C4b and C5. FEBS Lett 2007; 581:1716-1720.

48 Park SY, Kim KM, Lee JH, Seo SJ, Lee IH: Extracellular gelatinase of Enterococcus faecalis destroys a defense system in insect hemolymph and human serum. Infect Immun 2007;75:1861-1869.

49 Popadiak K, Potempa J, Riesbeck K, Blom AM: Biphasic effect of gingipains from Porphyromonas gingivalis on the human complement system. J Immunol 2007;178:72427250.

50 Slaney JM, Gallagher A, Aduse-Opoku J, Pell K, Curtis MA: Mechanisms of resistance of Porphyromonas gingivalis to killing by serum complement. Infect Immun 2006;74: 5352-5361.
Potempa M, Potempa J, Okroj M, Popadiak K, Eick S, Nguyen K-A, Riesbeck K, Blom AM: Binding of complement inhibitor C4bbinding protein contributes to serum resistance of Porphyromonas gingivalis. J Immunol 2008; 181:5537-5544.

52 Lathem WW, Bergsbaken T, Welch RA: Potentiation of $\mathrm{C} 1$ esterase inhibitor by StcE, a metalloprotease secreted by Escherichia coli O157:H7. J Exp Med 2004;199:1077-1087.

53 Yang D, Liu ZH, Tewary P, Chen Q, de la Rosa G, Oppenheim JJ: Defensin participation in innate and adaptive immunity. Curr Pharm Des 2007;13:3131-3139.

54 Eliasson M, Egesten A: Antibacterial chemokines - actors in both innate and adaptive immunity. Contrib Microbiol 2008;15:101117.

55 Nordahl EA, Rydengård V, Nyberg P, Nitsche DP, Mörgelin M, Malmsten M, Björck L, Schmidtchen A: Activation of the complement system generates antibacterial peptides. Proc Natl Acad Sci USA 2004;101: 16879-16884.

56 Pasupuleti M, Walse B, Nordahl EA, Mörgelin M, Malmsten M, Schmidtchen A: Preservation of antimicrobial properties of complement peptide $\mathrm{C} 3 \mathrm{a}$, from invertebrates to humans. J Biol Chem 2007;282:2520-2528.

57 Mak P: Hemocidins in a functional and structural context of human antimicrobial peptides. Front Biosci 2008;13:6859-6871.

58 Nordahl EA, Rydengård V, Mörgelin M, Schmidtchen A: Domain 5 of high molecular weight kininogen is antibacterial. J Biol Chem 2005;280:34832-34839.

-59 Rydengård V, Olsson AK, Mörgelin M, Schmidtchen A: Histidine-rich glycoprotein exerts antibacterial activity. FEBS J 2007; 274:377-389.

60 Malmsten M, Davoudi M, Schmidtchen A: Bacterial killing by heparin-binding peptides from PRELP and thrombospondin. Matrix Biol 2006;25:294-300.

61 Malmsten M, Davoudi M, Walse B, Rydengård V, Pasupuleti $M$, Mörgelin $M$, Schmidtchen A: Antimicrobial peptides derived from growth factors. Growth Factors 2007;25:60-70

62 Radek K, Gallo R: Antimicrobial peptides: natural effectors of the innate immune system. Semin Immunopathol 2007;29:27-43.

63 Nizet V: Antimicrobial peptide resistance mechanisms of human bacterial pathogens. Curr Issues Mol Biol 2006;8:11-26.

- 64 Karlsson C, Andersson ML, Collin M, Schmidtchen A, Björck L, Frick IM: SufA - a novel subtilisin-like serine proteinase of $\mathrm{Fi}$ negoldia magna. Microbiology 2007;153: 4208-4218.

65 Schmidtchen A, Frick IM, Andersson E, Tapper $\mathrm{H}$, Björck L: Proteinases of common pathogenic bacteria degrade and inactivate the antibacterial peptide LL-37. Mol Microbiol 2002;46:157-168. 
-66 Schmidtchen A, Frick IM, Björck L: Derma$\tan$ sulphate is released by proteinases of common pathogenic bacteria and inactivates antibacterial alpha-defensin. Mol Microbiol 2001;39:708-713.

-67 Park PW, Pier GB, Preston MJ, Goldberger O, Fitzgerald ML, Bernfield M: Syndecan-1 shedding is enhanced by LasA, a secreted virulence factor of Pseudomonas aeruginosa. J Biol Chem 2000;275:3057-3064.

68 Belas R, Manos J, Suvanasuthi R: Proteus mirabilis ZapA metalloprotease degrades a broad spectrum of substrates, including antimicrobial peptides. Infect Immun 2004;72: 5159-5167.

- 69 Carlisle MD, Srikantha RN, Brogden KA: Degradation of $\alpha$ - and $\beta$-defensins by culture supernatants of Porphyromonas gingivalis strain 381. J Innate Immun 2009;1:118122.

70 Bachrach G, Altman H, Kolenbrander PE, Chalmers NI, Gabai-Gutner M, Mor A, Friedman M, Steinberg D: Resistance of Porphyromonas gingivalis ATCC 33277 to direct killing by antimicrobial peptides is protease independent. Antimicrob Agents Chemother 2008;52:638-642.

-71 Taggart CC, Greene CM, Smith SG, Levine RL, McCray PB Jr, O’Neill S, McElvaney NG: Inactivation of human beta-defensins 2 and 3 by elastolytic cathepsins. J Immunol 2003; 171:931-937.

-72 Puklo M, Guentsch A, Hiemstra PS, Eick S, Potempa J: Analysis of neutrophil-derived antimicrobial peptides in gingival crevicular fluid suggests importance of cathelicidin LL37 in the innate immune response against periodontogenic bacteria. Oral Microbiol Immunol 2008;23:328-335.

-73 Sieprawska-Lupa M, Mydel P, Krawczyk K, Wójcik K, Puklo M, Lupa B, Suder P, Silberring J, Reed M, Pohl J, Shafer W, McAleese F, Foster T, Travis J, Potempa J: Degradation of human antimicrobial peptide LL-37 by Staphylococcus aureus-derived proteinases. Antimicrob Agents Chemother 2004;48: 4673-4679.

74 Lai Y, Villaruz AE, Li M, Cha DJ, Sturdevant DE, Otto M: The human anionic antimicrobial peptide dermcidin induces proteolytic defence mechanisms in staphylococci. Mol Microbiol 2007;63:497-506.

-75 Jin T, Bokarewa M, Foster T, Mitchell J, Higgins J, Tarkowski A: Staphylococcus aureus resists human defensins by production of staphylokinase, a novel bacterial evasion mechanism. J Immunol 2004;172:11691176.

76 Braff MH, Jones AL, Skerrett SJ, Rubens CE: Staphylococcus aureus exploits cathelicidin antimicrobial peptides produced during early pneumonia to promote staphylokinasedependent fibrinolysis. J Infect Dis 2007;195 1365-1372.
77 Vincents B, Onnerfjord P, Gruca M, Potempa J, Abrahamson M: Down-regulation of human extracellular cysteine protease inhibitors by the secreted staphylococcal cysteine proteases, staphopain A and B. Biol Chem 2007;388:437-446.

78 Nyberg P, Rasmussen M, Björck L: $\alpha-2-M a c-$ roglobulin-proteinase complexes protect Streptococcus pyogenes from killing by the antimicrobial peptide LL-37. J Biol Chem 2004;279:52820-52823.

79 Johansson L, Thulin P, Sendi P, Hertzén E, Linder A, Akesson P, Low DE, Agerberth B, Norrby-Teglund A: Cathelicidin LL-37 in severe Streptococcus pyogenes soft tissue infections in humans. Infect Immun 2008;76: 3399-3404.

80 Hwang BY, Varadarajan N, Li H, Rodriguez S, Iverson BL, Georgiou G: Substrate specificity of the Escherichia coli outer membrane protease OmpP. J Bacteriol 2007;189:522530 .

81 Guina T, Yi EC, Wang H, Hackett M, Miller SI: A PhoP-regulated outer membrane protease of Salmonella enterica serovar Typhimurium promotes resistance to alphahelical antimicrobial peptides. J Bacteriol 2000;182:4077-4086.

82 Bader MW, Navarre WW, Shiau W, Nikaido H, Frye JG, McClelland M, Fang FC, Miller SI: Regulation of Salmonella typhimurium virulence gene expression by cationic antimicrobial peptides. Mol Microbiol 2003;50: 219-230.

83 Lourbakos A, Chinni C, Thompson P, Potempa J, Travis J, Mackie EJ, Pike RN: Cleavage and activation of proteinase-activated receptor-2 on human neutrophils by gingipain- $\mathrm{R}$ from Porphyromonas gingivalis. FEBS Lett 1998;435:45-48.

84 Lourbakos A, Potempa J, Travis J, D’Andrea MR, Andrade-Gordon P, Santulli R, Mackie EJ, Pike RN: Arginine-specific protease from Porphyromonas gingivalis activates protease-activated receptors on human oral epithelial cells and induces interleukin- 6 secretion. Infect Immun 2001;69:5121-5130.

85 Lourbakos A, Yuan YP, Jenkins AL, Travis J, Andrade-Gordon P, Santulli R, Potempa J, Pike RN: Activation of protease-activated receptors by gingipains from Porphyromonas gingivalis leads to platelet aggregation: a new trait in microbial pathogenicity. Blood 2001; 97:3790-3797.

86 Holzhausen M, Spolidorio LC, Ellen RP, Jobin MC, Steinhoff M, Andrade-Gordon P, Vergnolle N: Protease-activated receptor-2 activation: a major role in the pathogenesis of Porphyromonas gingivalis infection. Am J Pathol 2006;168:1189-1199.

87 Kida Y, Higashimoto Y, Inoue H, Shimizu T, Kuwano K: A novel secreted protease from Pseudomonas aeruginosa activates NF- $\mathrm{B}$ through protease-activated receptors. Cell Microbiol 2008; 10:1491-504.
88 Dulon S, Leduc D, Cottrell GS, D’Alayer J, Hansen KK, Bunnett NW, Hollenberg MD, Pidard D, Chignard M: Pseudomonas aeruginosa elastase disables proteinase-activated receptor 2 in respiratory epithelial cells. Am J Respir Cell Mol Biol 2005;32:411-419.

89 Kida Y, Inoue H, Shimizu T, Kuwano K: Serratia marcescens serralysin induces inflammatory responses through protease-activated receptor 2. Infect Immun 2007;75: 164-174.

90 Kajikawa H, Yoshida N, Katada K, Hirayama F, Handa O, Kokura S, Naito Y, Yoshikawa T: Helicobacter pylori activates gastric epithelial cells to produce interleukin-8 via protease-activated receptor 2. Digestion 2007;76: 248-255.

-91 Sheets SM, Robles-Price AG, McKenzie RM, Casiano CA, Fletcher HM: Gingipaindependent interactions with the host are important for survival of Porphyromonas gingivalis. Front Biosci 2008;13:32153238 .

-92 Fitzpatrick R, Aprico A, Wijeyewickrema LC, Pagel CN, Wong D, Potempa J, Eleanor J. Mackie EJ, Pike RN: High molecular weight gingipains from Porphyromonas gingivalis induce cytokine responses from human macrophage-like cells via a nonproteolytic mechanism. J Innate Immun 2009;1:109-117.

93 Wolf M, Albrecht S, Märki C: Proteolytic processing of chemokines: implications in physiological and pathological conditions. Int J Biochem Cell Biol 2008;40:11851198.

94 Dean RA, Cox JH, Bellac CL, Doucet A, Starr AE, Overall CM: Macrophage-specific metalloelastase (MMP-12) truncates and inactivates ELR+ CXC chemokines and generates CCL2, 7, 8, and 13 antagonists: potential role of the macrophage in terminating PMN influx. Blood 2008;112: 3455-3464.

95 Mikolajczyk-Pawlinska J, Travis J, Potempa J: Modulation of interleukin-8 activity by gingipains from Porphyromonas gingivalis: implications for pathogenicity of periodontal disease. FEBS Lett 1998;440: 282-286.

-96 Leidal KG, Munson KL, Johnson MC, Denning GM: Metalloproteases from Pseudomonas aeruginosa degrade human RANTES, MCP-1, and ENA-78. J Interferon Cytokine Res 2003;23:307-318.

-97 Edwards RJ, Taylor GW, Ferguson M, Murray S, Rendell N, Wrigley A, Bai Z, Boyle J, Finney SJ, Jones A, Russell HH, Turner C, Cohen J, Faulkner L, Sriskandan S: Specific C-terminal cleavage and inactivation of interleukin- 8 by invasive disease isolates of Streptococcus pyogenes. J Infect Dis 2005; 192:783-790 
$\$ 98$ Zinkernagel AS, Timmer AM, Pence MA, Locke JB, Buchanan JT, Turner CE, Mishalian I, Sriskandan S, Hanski E, Nizet V: The IL-8 protease SpyCEP/ScpC of group A Streptococcus promotes resistance to neutrophil killing. Cell Host Microbe 2008;4: 170-178.

99 Chiang-Ni C, Wang CH, Tsai PJ, Chuang WJ, Lin YS, Lin MT, Liu CC, Wu JJ: Streptococcal pyrogenic exotoxin B causes mitochondria damage to polymorphonuclear cells preventing phagocytosis of group A Streptococcus. Med Microbiol Immunol 2006;195:55-63.

100 Söderberg JJ, von Pawel-Rammingen U: The streptococcal protease IdeS modulates bacterial IgGFc binding and generates $1 / 2 \mathrm{Fc}$ fragments with the ability to prime polymorphonuclear leucocytes. Mol Immunol 2008;45:3347-3353.

101 Vincents B, Vindebro R, Abrahamson M, von Pawel-Rammingen $\mathrm{U}$ : The human protease inhibitor cystatin $\mathrm{C}$ is an activating cofactor for the streptococcal cysteine protease IdeS. Chem Biol 2008;15:960-968.

102 Thulin P, Johansson L, Low DE, Gan BS, Kotb M, McGeer A, Norrby-Teglund A: Viable group A streptococci in macrophages during acute soft tissue infection. PLoS Med 2006;3:e53.

103 Kubica M, Guzik K, Koziel J, Zarebski M, Richter W, Gajkowska B, Golda A, MaciagGudowska A, Brix K, Shaw L, Foster T, Potempa J: A potential new pathway for Staphylococcus aureus dissemination: the silent survival of $S$. aureus phagocytosed by human monocyte-derived macrophages. PLoS One 2008;3:e1409.

104 Tada H, Sugawara S, Nemoto E, Takahashi N, Imamura T, Potempa J, Travis J, Shimauchi H, Takada H: Proteolysis of CD14 on human gingival fibroblasts by argininespecific cysteine proteinases from Porphyromonas gingivalis leading to down-regulation of lipopolysaccharide-induced interleukin-8 production. Infect Immun 2002; 70:3304-3307.

105 Cichy J, Bals R, Potempa J, Mani A, Puré E: Proteinase-mediated release of epithelial cell-associated CD44: extracellular CD44 complexes with components of cellular matrices. J Biol Chem 2002;277:44440-44447.

106 Chen Y, Hayashida A, Bennett AE, Hollingshead SK, Park PW: Streptococcus pneumoniae sheds syndecan-1 ectodomains through $\mathrm{ZmpC}$, a metalloproteinase virulence factor. J Biol Chem 2007;282:159167.
107 Andrian E, Grenier D, Rouabhia M: Porphyromonas gingivalis gingipains mediate the shedding of syndecan- 1 from the surface of gingival epithelial cells. Oral Microbiol Immunol 2006;21:123-128.

108 Leduc D, Beaufort N, de Bentzmann S, Rousselle JC, Namane A, Chignard M, Pidard D: The Pseudomonas aeruginosa LasB metalloproteinase regulates the human urokinase-type plasminogen activator receptor through domain-specific endoproteolysis. Infect Immun 2007;75: 3848-3858.

109 Smagur J, Guzik K, Magiera L, Bzowska M, Gruca M, Thøgersen IB, Enghild JJ, Potempa J: A new pathway of staphylococcal pathogenesis: apoptosis-like death induced by staphopain B ( $\mathrm{SspB}$ ) in human peripheral blood neutrophils and monocytes. J Innate Immun 2009;1:98-108.

110 Guzik K, Bzowska M, Smagur J, Krupa O, Sieprawska M, Travis J, Potempa J: A new insight into phagocytosis of apoptotic cells: proteolytic enzymes divert the recognition and clearance of polymorphonuclear leukocytes by macrophages. Cell Death Differ 2007; 14:171-182.

111 Otto BR, van Dooren SJ, Dozois CM, Luirink J, Oudega B: Escherichia coli hemoglobin protease autotransporter contributes to synergistic abscess formation and hemedependent growth of Bacteroides fragilis. Infect Immun 2002;70:5-10.

112 Smalley JW, Birss AJ, Szmigielski B, Potempa J: Mechanism of methaemoglobin breakdown by the lysine-specific gingipain of the periodontal pathogen Porphyromonas gingivalis. Biol Chem 2008;389:1235-1238.

$\checkmark 113$ Smalley JW, Birss AJ, Szmigielski B, Potempa J: Sequential action of R- and K-specific gingipains of Porphyromonas gingivalis in the generation of the haem-containing pigment from oxyhaemoglobin. Arch Biochem Biophys 2007;465:44-49.

114 Oido-Mori M, Rezzonico R, Wang PL, Kowashi Y, Dayer JM, Baehni PC, Chizzolini C: Porphyromonas gingivalis gingipain$\mathrm{R}$ enhances interleukin- 8 but decreases gamma interferon-inducible protein 10 production by human gingival fibroblasts in response to T-cell contact. Infect Immun 2001;69:4493-4501.

115 Chung WO, Hansen SR, Rao D, Dale BA: Protease-activated receptor signaling increases epithelial antimicrobial peptide expression. J Immunol. 2004;173:5165-5170.
16 Tancharoen S, Sarker KP, Imamura T, Biswas KK, Matsushita K, Tatsuyama S, Travis J, Potempa J, Torii M, Maruyama I: Neuropeptide release from dental pulp cells by RgpB via proteinase-activated receptor2 signaling. J Immunol 2005; 174:57965804.

117 Inomata $\mathrm{M}$, Into T, Ishihara $\mathrm{Y}$, Nakashima M, Noguchi T, Matsushita K: Argininespecific gingipain A from Porphyromonas gingivalis induces Weibel-Palade body exocytosis and enhanced activation of vascular endothelial cells through protease-activated receptors. Microbes Infect 2007;12-13: 1500-1506.

118 Yun LW, Decarlo AA, Hunter N: Blockade of protease-activated receptors on $\mathrm{T}$ cells correlates with altered proteolysis of CD27 by gingipains of Porphyromonas gingivalis. Clin Exp Immunol 2007;150:217-229.

119 Uehara A, Muramoto K, Imamura T, Nakayama K, Potempa J, Travis J, Sugawara S, Takada H: Arginine-specific gingipains from Porphyromonas gingivalis stimulate production of hepatocyte growth factor (scatter factor) through protease-activated receptors in human gingival fibroblasts in culture. J Immunol 2005;175:6076-6084.

120 Dommisch H, Chung WO, Rohani MG, Williams D, Rangarajan M, Curtis MA, Dale BA: Protease-activated receptor 2 mediates human beta-defensin 2 and CC chemokine ligand 20 mRNA expression in response to proteases secreted by Porphyromonas gingivalis. Infect Immun 2007;75: 4326-4333.

121 Giacaman RA, Nobbs AH, Ross KF, Herzberg MC: Porphyromonas gingivalis selectively up-regulates the HIV-1 coreceptor CCR5 in oral keratinocytes. J Immunol 2007;179:2542-2550.

122 Uehara A, Imamura T, Potempa J, Travis J, Takada H: Gingipains from Porphyromonas gingivalis synergistically induce the production of proinflammatory cytokines through protease-activated receptors with Toll-like receptor and NOD1/2 ligands in human monocytic cells. Cell Microbiol 2008;10:1181-1189.

123 Uehara A, Naito M, Imamura T, Potempa J, Travis J, Nakayama K, Takada H: Dual regulation of interleukin-8 production in human oral epithelial cells upon stimulation with gingipains from Porphyromonas gingivalis. J Med Microbiol 2008;57:500-507. 